\title{
Bradykinin and its role in osteoarthritis
}

\author{
L. De Falco, A. Fioravanti, M. Galeazzi, S. Tenti \\ Rheumatology Unit, Department of Medicine, Surgery and Neurosciences, University of Siena, Italy
}

\begin{abstract}
SUMMARY
Osteoarthritis (OA), the most common joint disorder, is a disease involving all the articular structures. It presents both degenerative and inflammatory aspects. Recently, the important role of Bradykinin (BK), a phlogistic mediator, has been proposed in the pathophysiology of OA. In our review, we summarized the currently available information on the mechanisms of action of BK in OA by linking its $\mathrm{B}_{2}$ receptors. Then, we analyzed the data about the effects of BK in synoviocytes and chondrocytes cultures. Furthermore, we described the action of $\mathrm{B}_{2}$ receptor antagonists (Icatibant and Fasitibant), presenting them as new promising symptom-anddisease-modifying agents in the treatment of OA. However, more in vitro, animal model and clinical studies, are needed to better understand the mechanisms of action as well as the efficacy and tolerability of the $\mathrm{B}_{2}$ receptor antagonists in $\mathrm{OA}$.
\end{abstract}

Key words: Bradykinin $B_{2}$ receptor antagonists, Bradykinin, Fasitibant, Icatibant, osteoarthritis.

Reumatismo, 2013; 65 (3): 97-104

\section{INTRODUCTION}

$\mathrm{O}$ steoarthritis (OA) is the most prevalent disease of articular joints in older adults in industrialized countries (1). The number of people with symptomatic OA is likely to increase due to the aging of the population. This disease plays an important medical and social role, causing deformity and joint disability, especially when it affects the knee and hip (2).

The main features of OA are degeneration and loss of articular cartilage, but all the joint components, including the bone, synovial lining, ligaments, tendons and periarticular tissue undergo structural and functional alterations during the course of OA progression (3). Cartilage breakdown is attributable to an imbalance between synthetic (anabolic) and resorptive (catabolic) activities of the resident chondrocytes. The catabolic processes exceed anabolic processes leading to a net decrease in extracellular matrix components (ECM) (type II collagen and proteoglicans) (3-6). Although the pathogenesis of OA is not fully understood, current knowledge indicates that many catabolic and proinflammatory factors contribute to the degradative cascade in OA. The spectrum of these factors includes different cytokines such as interleukin- $1 \beta$ (IL-1 $\beta$ ), interleukin-6 (IL-6), tumor necrosis factor a (TNF-a), chemokines such as interleukin-8 (IL-8), numerous metalloproteinases (MMP) (MMP-3 MMP-9 MMP13), prostaglandin $\mathrm{E}_{2}\left(\mathrm{PGE}_{2}\right)$ and nitric oxide (NO) (5). Recently, several evidences suggest the involvement of bradykinin $(\mathrm{BK})$ and $\mathrm{B}_{2}$ receptors in the pathophysiology of OA $(7,8)$. The aim of this study is to summarize preclinical and clinical evidences, which supports the hypothesis for a role of $\mathrm{BK}$ in OA pathogenesis.

\section{BRADYKININ, KININS AND THEIR RECEPTORS}

Kinins are peptides involved in both acute and chronic inflammation inducing pain, edema formation, vasodilation, and prostaglandins synthesis.

They are produced by specific proteases such as plasma and tissue kallikrein. Kallikrein-kinin system is activated by coagulation factor XII, a self-activating protease that converts prekallikrein in kallikrein. Kallicrein, in turn, activates the coagulation factor XII causing a positive feedback. Two different cascades and specific pre-
Corresponding author: Dr. Antonella Fioravanti Rheumatology Unit Department of Medicine Surgery and Neurosciences Policlinico "Le Scotte" Viale Bracci, 1 - 53100 Siena, Italy E-mail: fioravanti7@virgilio.it 
cursors produce kinins: one in the plasma, the high molecular weight kininogen, and another in the tissues, the low molecular weight kininogen (9) (Fig. 1).

The high molecular weight kininogen generates, by plasma kallikrein, BK, a nonapeptide whose aminoacid sequences is Arg-Pro-Pro-Gly-Phe-Ser-Pro-Phe-Arg, whereas low molecular weight kininogen leads to the formation of kallidin (LysBK), having amino-terminal additional lysine residual.

BK and Lys-BK are rapidly degraded by different enzymes, such as the carboxypeptidase $\mathrm{M}$ and $\mathrm{N}$, which cleave off the carboxy-terminal arginine to produce the active desArg metabolites $(9,10)$ (Fig. 1). There are at least two kinins receptors, $\mathrm{B}_{1}$ and $\mathrm{B}_{2}$, which belong to the Class I of $\mathrm{G}$ protein coupled receptors (IUPHAR) (11). The $\mathrm{B}_{1}$ receptors mediate the effect of $\mathrm{C}$ terminal desArg metabolites, while the $\mathrm{B}_{2}$ receptors mediate the effect of $\mathrm{BK}$ and Lys-BK (12) (Fig. 1).

A recent study conducted in 2012 by Chen et al. (13) analyzed the role of $+9 /-9$ polymorphisms of $\mathrm{B}_{2}$ receptor $\left(\mathrm{BDKRB}_{2}\right)$ gene in 245 patients with primary knee OA and 264 healthy controls. The Authors reported that $-9 /-9$ genotype had a significantly in-

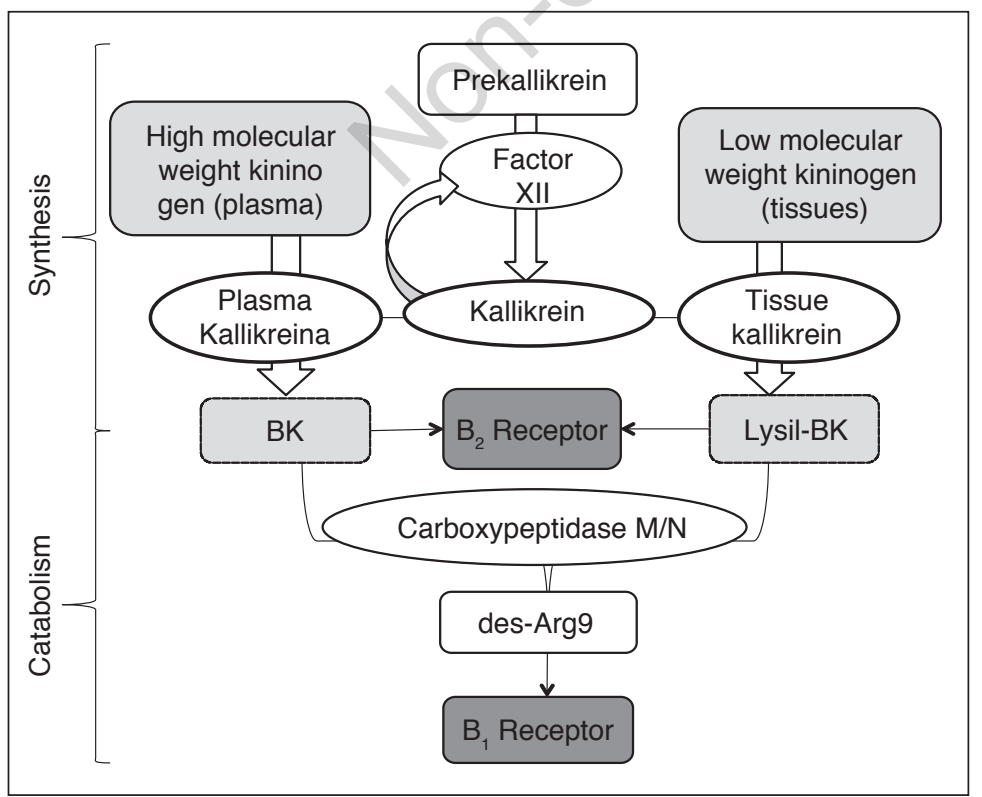

Figure 1 - Synthesis and catabolism of Bradykinin. creased risk for knee OA, when compared with $+9 /+9$ genotype, and that BDKRB polymorphism was also associated with $\mathrm{OA}$ radiographic severity. This finding suggests that $\mathrm{BDKRB}_{2}+9 /-9$ polymorphisms may be used as a genetic marker for the onset and development of OA.

\section{BRADYKININ IN THE SYNOVIAL FLUID OF OSTEOARTHRITIS PATIENTS}

Initially evidence of the presence of BK in the synovial fluid of patients affected by arthritis of different etiologies, including OA, was early presented in 1967 by Melmon et al. (14). Later, Eisen (15) found the presence of $\mathrm{BK}$ in 33 out of 82 synovial fluids of patients with rheumatoid arthritis (RA) and in 2 out of 27 fluids from joint effusions caused by OA or trauma.

In 1992, Bond et al. (16) reported that the synovial BK content of patients with RA ranged between 1 and $60 \mathrm{nM}$. Later, Nishimura et al. (17) demonstrated the high rate of $\mathrm{BK}$ in patients with internal derangements and OA of temporomandibular joint and, for this reason, BK might be a useful index of the degree of synovitis. A recent preliminary study conducted by Meini et al. (18) quantified BK levels in knee synovial fluids of patients with gonarthrosis, finding the basal BK content ranging between 281 and $563 \mathrm{pg} /$ $\mathrm{mL}$ (mean 422) and generated BK content ranging 2591-4264 pg/mL (mean 3427). Moreover, a significant positive correlation was found between BK levels, both the basal and generated ones, and the contents of IL-6, one of the most important cytokines involving in OA.

\section{BRADIKININ AND B RECEPTORS IN HYPERALGESIA AND INFLAMMATION}

The algogenic and proinflammatory activity of BK is linked to the activation and sensitization of nociceptive afferent nerve 
terminals, as demonstrated by Steranka et al. in 1988 (19). BK, through $\mathrm{B}_{2}$ receptor interaction, activates the phospholipase $\mathrm{C}$ (PLC) with consequent inositol phosphate (IP) hydrolysis and diacylglycerol (DAG) production, which in turn potentiates the activation and increases the expression of vanilloid TRPV1 receptors (19-25).

BK has also been shown to evoke calcitonin gene related peptide (CGRP) release in knee joints of mice, which spontaneously developed OA, and to produce a significantly higher release of $\mathrm{PGE}_{2}$ in joints of animals treated with collagenase as a model of OA (26). In 1993, Gotoh et al. (27) showed that the intra-articular administration of BK could induce hyperalgesia in rats. Consecutive studies of Davis and Perkins $(28,29)$ demonstrated that the hyperalgesia, produced by intra-articular administration of substances such as capsaicin or substance $\mathrm{P}$ that stimulate the nociceptive sensory fibers, could be blocked by systemic treatment with Icatibant, a $\mathrm{B}_{2}$ receptor antagonist (30). The intra-articular injection of the synthetic peptide of BK into dog knee $(500 \mu \mathrm{g}$ in $1 \mathrm{~mL})$ caused local warmth and swelling within a few minutes of administration, as a consequence of hyperemia of synovial membranes and increased synovial fluid demonstrating the involvement of BK in inflammatory events (14). Later studies in the rat synovium demonstrated that intra-articular administration of $\mathrm{BK}$ induced plasma extravasation and neutrophils accumulation (31-33) more potently than other inflammatory mediators such as substance $\mathrm{P}$, histamine, and CGRP (34). BK-induced plasma extravasation resulted due to a direct stimulation of $\mathrm{B}_{2}$-type $\mathrm{BK}$ receptor, which is likely to be located on the vascular endothelial cells and/or smooth muscle and could be inhibited by the selective $B_{2}$ receptor antagonist (35).

\section{KININS EFFECTS ON SYNOVIOCYTES}

The synovial membrane presents in its superficial layer a unique cellular lining, the synovial intima, which is one of three cells deep. The synovial intima contains two types of synoviocytes. Type A synoviocytes, which are derived from blood-borne mononuclear cells, can be considered as resident macrophages owing to their ability to actively phagocytose cell debris and wastes in the joint cavity and antigen-presenting ability. Type B synoviocytes cells are involved in the production of specialized matrix constituents, including hyaluronan, collagens, and fibronectin for the intimal interstitium and synovial fluid (36). Bathon et al. (37), in 1991, first characterized the number affinity and receptor subtype of specific kinin binding sites in intact human synovial tissue and in cultured human synovial cells. Furthermore, they examined the effect of IL-1 treatment on these binding parameters. Specific saturable tritiated $\mathrm{BK}$ binding sites in intact synovia were identified by autoradiographic localization and were present in much higher density in RA than in OA synovia. The kinin binding site on the synovial cells belonged to the $\mathrm{B}_{2}$ class of kinin receptors. The treatment with IL-1 resulted to enhance specific tritiated BK binding in synovial cells. The presence of $\mathrm{B}_{2}$ receptors on human synoviocytes was further confirmed by Uhl et al. (38) and Cassim et al. (39), who performed a study to localize $\mathrm{B}_{2}$ receptors. These receptors were observed in the synovial lining cells, fibroblasts, and endothelial lining cells of blood vessels, whereas no evidence supported the presence of the $\mathrm{B}_{1}$ receptor subtype.

Bellucci et al. (40) conducted a study to investigate new proinflammatory actions by BK in human fibroblast-like synoviocytes. In particular, the Authors focused on the ability of BK to induce IL- 6 and IL-8 production by synoviocytes and the mechanism involved. They showed that BK, after a long-term incubation, was able to increase the release of IL- 6 and IL-8 from human synoviocytes in a concentration-dependent manner. Furthermore, the Authors presented pharmacological evidence that PLC and nuclear factor kappaB (NF- $\mathrm{BB})$ activations were involved in the $\mathrm{BK}$-mediated release of IL-8, as previously described for IL-6 in other studies. 
Moreover, BK induced the release of arachidonic acid (AA), and $\mathrm{PGE}_{1}$ and $\mathrm{F}$ were synergistically potentiated when the cells were cultured in the presence of higher concentrations of serum and when the BK was co-administered with $\mathrm{PGE}_{1}$, thus suggesting that some other factors may be involved in activating the adenylylcyclase pathways in human synovial fibroblasts $(41,42)$.

Meini et al. (43) demonstrated that the incubation of synoviocytes with BK induced a sustained production of $\mathrm{PGE}_{2}$ and transient cyclooxygenase-2 (COX-2) gene expression. The co-incubation of cells with $\mathrm{BK}$ and IL-1 $\beta$ induced a greater increase in released $\mathrm{PGE}_{2}$ and $\mathrm{COX}-2$ gene and protein expression, indicating a synergistic rather than an additive effect. These potentiating effects of $\mathrm{BK}$ on $\mathrm{PGE}_{2}$ production and increased COX-2 expression produced by IL-1 $\beta$ were $B_{2}$-receptor-mediated because Fasitibant could be prevent them.

\section{KININS EFFECTS ON CHONDROCYTES}

In 2011, Meini et al. (44) conducted a study on rat and human articular chondrocytes to define the pharmacological profile of $\mathrm{BK}$, its receptors, and some of its analogs and antagonists, especially the recent nonpeptide $\mathrm{B}_{2}$ receptor antagonist Fasitibant or MEN16132. They used tritiated BK to pharmacologically characterize the BK $\mathrm{B}_{2}$ receptor. They compared the power of MEN16132 with Icatibant, by measuring the accumulation of IP and the release of IL- 6 and IL- 8 induced by BK. The density of $\mathrm{BK}$ receptors was high and greater in human chondrocytes, when compared with rat chondrocytes. The inhibitors MEN16132 and Icatibant showed similar binding affinity. The Authors also observed greater accumulation of IP induced by BK in human chondrocytes, when compared with those in rats and the antagonist MEN16132 was more potent than Icatibant in inhibiting accumulation of IP. Furthermore, after incubation for $24 \mathrm{~h}$ in cultured human chondrocytes, BK increased the release of IL-6 and IL-8, an effect which was neutralized by MEN16132, but not by the antagonist of the receptor $B_{1}$. Furthermore, the Authors investigated the mechanisms involved in the IL- 6 and IL- 8 release induced by BK in human chondrocytes by pre-treating these cells with different inhibitors. Human chondrocytes were exposed to pretreatment with the nonselective COX inhibitor indomethacin, the nonselective lipoxygenase nordihydroguaiaretic acid (NDGA), or the glucocorticoid dexamethasone before BK stimulation. The release of IL-6 induced by BK was partially inhibited by indomethacin and NDGA, but it was not the same for the release of IL-8.

Dexamethasone has been shown to reduce both the release of IL- 6 and IL- 8 stimulated by BK.

In conclusion, this study demonstrated the important role of BK in inflammatory and degenerative process of $\mathrm{OA}$ and advanced the hypothesis of a possible use of $\mathrm{BK} \mathrm{B}_{2}$ receptor antagonists in the treatment of OA.

\section{BRADIKININ B 2 RECEPTOR ANTAGONISTS AND THEIR CLINICAL IMPLICATIONS}

Considering the important role of BK in inflammation and its activity on different kinds of joint cells, $\mathrm{B}_{2}$ receptor antagonists may represent a new therapeutic strategy in OA (45). Icatibant is a synthetic decapeptide and a potent, stable, specific, and longacting antagonist of the $\mathrm{BK} \mathrm{B}_{2}$ receptor; it is currently used for angioedema attacks $(46,47)$ (Fig. 2).

Over the years, much of the pharmaceutical research was aimed at the identification of nonpeptidic small molecules, which are more useful from a clinical point of view (48-50). These studies led to the synthesis of a nonpeptide $\mathrm{B}_{2}$ receptor antagonist, known as MEN16132 or Fasitibant (Fig. 2). Different studies were conducted to investigate the pharmacological characterization (affinity, selectivity, and antagonist potency) of MEN16132 in various animal and human tissues (i.e. mouse lung and 
ileum smooth muscle, human and rat urinary bladder, rabbit and pig ileal smooth muscle) (51-55).

MEN16132 is a new potent and selective nonpeptide $\mathrm{BK}_{2}$ receptor antagonist (51$55)$.

Meini et al. (46) recently compared the different pharmacological effects of Icatibant and Fasitibant on human synoviocytes BK $\mathrm{B}_{2}$ receptor.

First, the reversibility of the antagonist action in blocking $\mathrm{B}_{2}$ receptors was compared through functional experiments (IP accumulation assay), and then through radioligand binding experiments, the affinities of the two antagonists were compared using a panel of point-mutated receptors.

The results of the study showed that MEN16132 was more potent than Icatibant with regard to its slower reversibility from the $\mathrm{B}_{2}$ receptor compartment, and this was due to the interaction of MEN16132 at a deeper level in the transmembrane regions of the receptor.

In addition to the in vitro studies, clinical studies were also conducted to assess the efficacy and tolerability of $\mathrm{BK} \mathrm{B}_{2}$ receptor antagonists.

In 2004, Flechtenmacher et al. (56) performed a double-blind placebo-controlled Phase II study on 58 patients with symptomatic knee OA in which a single intra-articular injection of the antagonist Icatibant $(90 \mu \mathrm{gr} / \mathrm{mL})$ reduced pain intensity more effectively than the placebo. Furthermore, the Authors reported that the analgesic activity of Icatibant was more significant on the pain perceived during activity than on pain at rest. This evidence was later confirmed by another randomized doubleblind placebo-controlled study in 2009 (57).

With regard to the efficacy of MEN16132, preclinical data are being confirmed by an ongoing clinical study (multicenter randomized, double-blind, placebo-controlled), named ALBATROSS, on patients with knee OA treated with intra-articular administration of MEN16132. This study is registered in Clinical Trials database (www.ClinicalTrials.gov; number: NCTO1091116).

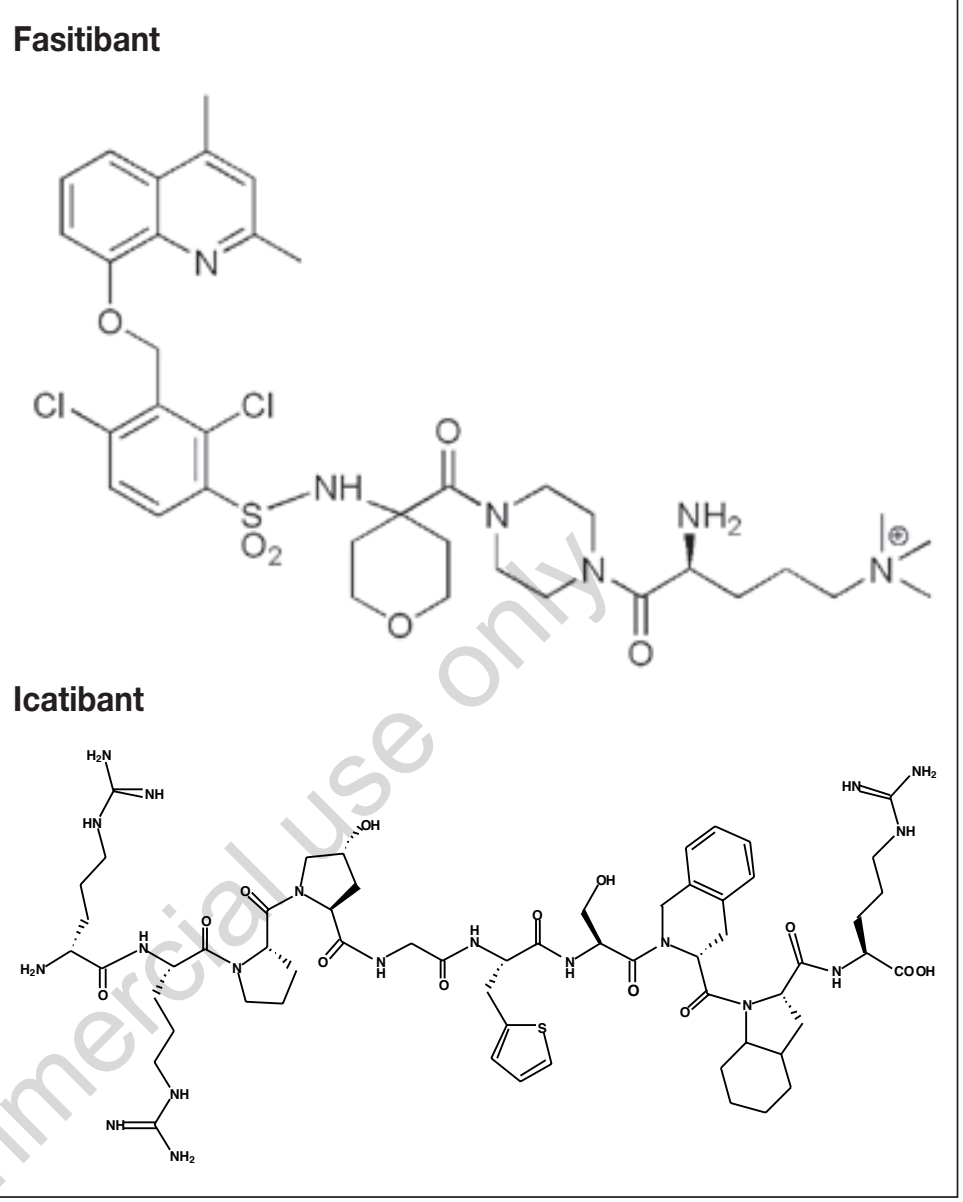

Figure 2 - Chemical structure of the antagonists of $B_{2}$ receptor (Icatibant and Fasitibant).

\section{CONCLUSIONS}

In conclusion, our literature review demonstrated that $\mathrm{BK}$ is an important mediator of articular pain and inflammation, which stimulates the release of inflammatory and catabolic cytokines by articular chondrocytes.

These findings, in agreement with preclinical studies, lead to the notion that the BK $\mathrm{B}_{2}$ receptor antagonists could be important symptomatic drugs in the treatment of $\mathrm{OA}$, capable of controlling pain and improving joint function.

Furthermore, $\mathrm{BK}_{2}$ receptor antagonists, acting directly on chondrocyte and reducing the release of proinflammatory cytokines (IL-6, IL-8), may also represent new disease modifying osteoarthritis drugs 
(DMOADs) for the treatment of OA, decreasing or stopping the progression of the disease $(52,53)$.

$\mathrm{BK} \mathrm{B}_{2}$ receptor antagonists therefore appear as a promising therapeutic strategy in OA.

However, further in vitro, animal model, and clinical studies, are needed to better understand the mechanisms of action as well as the efficacy and tolerability of the $\mathrm{B}_{2}$ receptor antagonists in $\mathrm{OA}(58,59)$.

Conflict of interests: the authors report no conflict of interests.

\section{REFERENCES}

1. Zhang Y, Jordan JM. Epidemiology of osteoarthritis. Clin Geriatr Med. 2010; 26: 355-69.

2. Bijlsma JW, Berenbaum F, Lafeber FP. Osteoarthritis: an update with relevance for clinical practice. Lancet. 2011; 18: 2115-26.

3. Martel-Pelletier J. Pathophysiology of osteoarthritis. Osteoarthritis Cartilage. 2004; 12 (Suppl. A): 31S-33S.

4. Goldring SR, Goldring MB. The role of cytokines in cartilage matrix degeneration in osteoarthritis. Clin Orthop Relat Res. 2004; 427: 27-36.

5. Daheshia M, Yao JQ. The Interleukin $1 \beta$ pathway in the pathogenesis of osteoarthritis. J Rheumatol. 2008; 35: 2306-12.

6. Cawston TE, Young DA. Proteinases involved in matrix turnover during cartilage and bone breakdown. Cell Tissue Res. 2010; 339: 22135.

7. Wenham CY, Conaghan PG. New horizons in osteoarthritis. Age Ageing. 2013; 42: 272-8.

8. Meini S, Maggi CA. Knee osteoarthritis: a role for bradykinin? Inflamm Res. 2008; 57: 351-61.

9. Bhoola KD, Figueroa CD, Worthy K. Bioregulation of kinins: kallikreins, kininogens, and kininases. Pharmacol Rev. 1992; 44: 1-80.

10. Moreau ME, Garbacki N, Molinaro G, et al. The kallikrein-kinin system: current and future pharmacological targets. J Pharmacol Sci. 2005; 99: 6-38.

11. Foord SM, Bonner TI, Neubig RR, et al. International Union of Pharmacology. XLVI. G protein-coupled receptor list. Pharmacol Rev. 2005; 57: 279-88.

12. Regoli D, Barabé J. Pharmacology of bradykinin and related kinins. Pharmacol Rev. 1980; 32: 1-46.

13. Chen S, Zhou Y, Li J, et al. The effect of Bradykinin B2 receptor polymorphism on the susceptibility and severity of osteoarthritis in a Chinese Cohort. J Biomed Biotechnol. 2012; 2012: 597-637.

14. Melmon KL, Webster ME, Goldfinger SE, Seegmiller JE. The presence of a kinin in inflammatory synovial effusion from arthritides of varying etiologies. Arthritis Rheum. 1967; 10: $13-20$

15. Eisen V. Plasma kinins in synovial exudates. Br J Exp Pathol. 1970; 51: 322-7.

16. Bond AP, Breipohl G, Worthy K, et al. Metabolism and characterisation of kinins and Hoe 140 (kinin antagonist) in the synovial fluid of patients with inflammatory joint diseases. Agents Actions Suppl. 1992; 38: 582-9.

17. Nishimura M, Segami N, Kaneyama K, et al. Relationships between pain-related mediators and both synovitis and joint pain in patients with internal derangements and osteoarthritis of the temporomandibular joint. Oral Surg Oral Med Oral Pathol Oral Radiol Endod. 2002; 94: 328-32.

18. Meini S, Bellucci F, Cucchi P, et al. Bradykinin contents in the synovial fluid from patients affected by knees osteoarthritis. Proceedings of Kinin 2012 Conference; 2012 Jun 21-23; Paris.

19. Steranka LR, Manning DC, DeHaas CJ, et al. Bradykinin as a pain mediator: receptors are localized to sensory neurons, and antagonists have analgesic actions. Proc Natl Acad Sci USA. 1988; 85: 3245-9.

20. Dray A, Bettaney J, Forster P, Perkins MN. Bradykinin-induced stimulation of afferent fibres is mediated through protein kinase C. Neurosci Lett. 1988; 91: 301-7.

21. Dray A. Kinins and their receptors in hyperalgesia. Can J Physiol Pharmacol. 1997; 75: 704-12.

22. Cesare P, McNaughton P. A novel heat-activated current in nociceptive neurons and its sensitization by bradykinin. Proc Natl Acad Sci USA. 1996; 93: 15435-9.

23. Cesare P, McNaughton P. Peripheral pain mechanisms. Curr Opin Neurobiol. 1997; 7: 493-9.

24. Premkumar LS, Ahern GP. Induction of vanilloid receptor channel activity by protein kinase C. Nature. 2000; 408: 985-90.

25. Chuang HH, Prescott ED, Kong H, et al. Bradykinin and nerve growth factor release the capsaicin receptor from PtdIns (4,5) P2-mediated inhibition. Nature. 2001; 41: 957-62.

26. Averbeck B, Rudolphi K, Michaelis M. Osteoarthritic mice exhibit enhanced prostaglandin E2 and unchanged calcitonin gene-related peptide release in a novel isolated knee joint model. J Rheumatol. 2004; 31: 2013-20.

27. Gotoh S, Onaya J, Abe M, et al. Effects of the molecular weight of hyaluronic acid and its action mechanisms on experimental joint pain in rats. Ann Rheum Dis. 1993; 52: 817-22.

28. Davis AJ, Perkins MN. The involvement of 
bradykinin $\mathrm{B} 1$ and $\mathrm{B} 2$ receptor mechanisms in cytokine-induced mechanical hyperalgesia in the rat. Br J Pharmacol. 1994; 113: 63-8.

29. Davis AJ, Perkins MN. Substance P and capsaicin-induced mechanical hyperalgesia in the rat knee joint; the involvement of bradykinin $\mathrm{B}_{1}$ and $\mathrm{B}_{2}$ receptors. Br J Pharmacol. 1996; 118: 2206-12.

30. Tonussi CR, Ferreira SH. Tumour necrosis factor-alpha mediates carrageenin-induced knee-joint incapacitation and also triggers overt nociception in previously inflamed rat knee-joints. Pain. 1999; 82: 81-7.

31. Green PG, Luo J, Heller PH, Levine JD. Effect of E-type prostaglandins on bradykinininduced plasma extravasation in the knee joint of the rat. Eur J Pharmacol. 1994; 252: 127 32.

32. Lo EJ, Green PG, Miao FJ, et al. Bradykinininduced neurogenic migration of neutrophils into the rat knee joint. Neuroreport. 1999; 10: 3821-4.

33. Grond S, Demopulos G, Herz J, Pierce Palmer P. Inhibition of synovial plasma extravasation by preemptive administration of an antiinflammatory irrigation solution in the rat knee. Anesth Analg. 2001; 92: 1301-6.

34. Cruwys SC, Kidd BL, Mapp PI, et al. The effects of calcitonin gene-related peptide on formation of intra-articular oedema by inflammatory mediators. Br J Pharmacol. 1992; 107: 116-9.

35. Cambridge H, Brain SD. Mechanism of bradykinin-induced plasma extravasation in the rat knee joint. Br J Pharmacol. 1995; 115: 641-7.

36. Iwanaga T, Shikichi M, Kitamura H, et al. Morphology and functional roles of synoviocytes in the joint. Arch Histol Cytol. 2000; 63: 17-31.

37. Bathon JM, Manning DC, Goldman DW, et al. Characterization of kinin receptors on human synovial cells and upregulation of receptor number by interleukin-1. J Pharmacol Exp Ther. 1992; 260: 384-92.

38. Uhl J, Singh S, Brophy L, et al. Role of bradykinin in inflammatory arthritis: identification and functional analysis of bradykinin receptors on human synovial fibroblasts. Immunopharmacology. 1992; 23: 131-8.

39. Cassim B, Naidoo S, Ramsaroop R, Bhoola KD. Immunolocalization of bradykinin receptors on human synovial tissue. Immunopharmacology. 1997; 36: 121-5.

40. Bellucci F, Cucchi P, Catalani C, et al. Novel effects mediated by bradykinin and pharmacological characterization of bradykinin B2 receptor antagonism in human synovial fibroblasts. Br J Pharmacol. 2009; 158: 19962004.

41. Fahey JV, Ciosek CP Jr, Newcombe DS. Human synovial fibroblasts: the relationships between cyclic AMP, bradykinin, and prostaglandins. Agents Actions. 1977; 7: 255-64.

42. Fahey JV, Newcombe DS. The effect of 7-oxa13 prostynoic acid in the mechanism of action of bradykinin in human synovial fibroblasts. Prostaglandins. 1978; 15: 333-42.

43. Meini S, Cucchi P, Tinti L, et al. Fasitibant prevents the bradykinin and interleukin $1 \beta$ synergism on prostaglandin E2 release and cyclooxygenase 2 expression in human fibroblast-like synoviocytes. Naunyn Schmiedebergs Arch Pharmacol. 2012; 385: 777-86.

44. Meini S, Cucchi P, Catalani C, et al. Bradykinin and $\mathrm{B} 2$ receptor antagonism in rat and human articular chondrocytes. Br J Pharmacol. 2011; 162: 611-22.

45. Bonnet CS, Walsh DA. Osteoarthritis, angiogenesis and inflammation. Rheumatology (Oxford). 2005; 44: 7-16.

46. Meini S, Bellucci F, Catalani C, et al. Comparison of the molecular interactions of two antagonists, MEN16132, or Icatibant, at the human kinin $\mathrm{B} 2$ receptor. $\mathrm{Br} \mathrm{J}$ Pharmacol. 2011; 162: 1202-12.

47. Rhaleb NE, Rouissi N, Jukic D, et al. Pharmacological characterization of a new highly potent B2 receptor antagonist (HOE 140: DArg-(Hyp3, Thi5, D-Tic7, Qic8) bradykinin). Eur J Pharmacol. 1992; 210: 115-20.

48. Dziadulewicz EK. Non-peptide ligands for bradykinin receptors. Expert Opin Ther Patent. 2005; 15: 829-59.

49. Abraham WM, Scuri M, Farmer SG. Peptide and non-peptide bradykinin receptor antagonists: role in allergic airway disease. Eur J Pharmacol. 2006; 533: 215-21.

50. Fincham CI, Bressan A, Paris M, et al. Bradykinin receptor antagonists- a review of the patent literature. Expert Opin Ther Pat. 2009; 19: 919-41.

51. Cucchi P, Meini S, Bressan A, et al. MEN16132, a novel potent and selective nonpeptide antagonist for the human bradykinin B2 receptor. In vitro pharmacology and molecular characterization. Eur J Pharmacol. 2005; 528: 7-16.

52. Meini S, Cucchi P, Bellucci F, et al. Comparative antagonist pharmacology at the native mouse bradykinin $\mathrm{B} 2$ receptor: radioligand binding and smooth muscle contractility studies. Br J Pharmacol. 2007; 150: 313-20.

53. Meini S, Cucchi P, Catalani C, et al. Pharmacology characterization of the bradykinin B2 receptor antagonist MEN16132 in rat in vitro bioassays. Eur J Pharmacol. 2009; 615: 10-6.

54. Meini S, Cucchi P, Catalani C, et al. Radioligand binding characterization of the bradykinin $\mathrm{B} 2$ receptor in the rabbit and pig ileal smooth musce. Eur J Pharmacol. 2010; 635: 34-9.

55. Cialdai C, Giuliani S, Valenti C, et al. Effect of intra-articular MEN16132, a kinin $\mathrm{B}_{2}$ receptor 
antagonist, on nociceptive response in monosodium iodoacetate-induced experimental osteoarthritis in rats. J Pharmacol Exp Ther. 2009; 331: 1025-32.

56. Flechtenmacher J, Talke M, Veith D, et al. Bradykinin-receptor-inhibition-a therapeutic option in osteoarthritis? Osteoarthr Cartil. 2004; 12 (Suppl. 137): S332.

57. Song IH, Althoff CE, Hermann KG, et al. Contrast-enhanced ultrasound in monitoring the efficacy of a bradykinin receptor-2 antagonist in painful knee osteoarthritis compared to magnetic resonance imaging. Ann Rheum Dis. 2009; 68: 75-83.

58. Martel-Pelletier J, Wildi LM, Pelletier JP. Future therapeutics for osteoarthritis. Bone. 2012; 51: 297-311.

59. Fioravanti A. I condroprotettori: meccanismo d'azione e problemi aperti. Reumatismo. 1993; 45: 306-18. 